\title{
CINÉTICA DE DEGRADAÇÃO DOS COMPOSTOS BIOATIVOS DA AMORA-PRETA DURANTE O PROCESSO DE SECAGEM CONVECTIVA
}

\author{
C. M. S. COUGO ${ }^{1}$, H. LUNARDI ${ }^{1}$ e G. S. ROSA ${ }^{2}$ \\ ${ }^{1}$ Universidade Federal do Pampa, Discente do Curso de Engenharia Química \\ ${ }^{2}$ Universidade Federal do Pampa, Docente do Curso de Engenharia Química \\ E-mail para contato: matheuspetarca@ hotmail.com
}

\begin{abstract}
RESUMO - Os compostos bioativos apresentam grande valor à saúde humana, pois possuem entre suas propriedades, caráter antioxidante. A amora-preta é um fruto de elevado valor nutritivo e alta concentração destes compostos, entre eles, as antocianinas que são consideradas pigmentos naturais. Entretanto, devido ao elevado conteúdo de umidade presente na fruta, essas possuem um curto prazo de validade. Logo, o objetivo deste trabalho foi avaliar o comportamento das antocianinas presentes na amora-preta quando submetidas ao processo de secagem. Este processo foi realizado em um secador de leito fixo com escoamento paralelo de ar, na temperatura de $80{ }^{\circ} \mathrm{C}$ e velocidade do ar de $2 \mathrm{~m} / \mathrm{s}$. Para avaliar a cinética de degradação das antocianinas realizou-se ensaios de secagem com diferentes tempos e para a quantificação das mesmas foi utilizado o método de Fuleki e Francis, que utiliza etanol como solução extratora. Os resultados obtidos indicaram que o conteúdo de antocianinas da amostra in natura é de $466 \mathrm{mg} / 100 \mathrm{~g}$ s.s., enquanto que a amostra seca apresentou redução de $24,25 \%$ neste valor.
\end{abstract}

\section{INTRODUÇÃO}

Estudos referentes ao comportamento de alimentos expostos a processos físicos têm se tornados essenciais no cenário alimentício dos dias atuais, uma vez que tem se verificado uma necessidade cada vez maior de nutrientes nas refeições de uma forma saudável, acessível economicamente, agradável ao consumidor e com alimentos de com maior duração e prazo de validade. Dentre estes nutrientes, podem-se citar os chamados compostos bioativos, que são compostos fitoquímicos produzidos pelas plantas a partir de funções secundárias, como quando a planta se encontra em uma situação de stress, fenólica, denominados polifenóis (Harbone e Williams, 2000). Os compostos fitoquímicos produzidos pelas plantas que proporcionam algum benefício à saúde humana são denominados como bioativos.

Estes compostos estão presentes na composição de diversas frutas, bem como na amorapreta, e possuem um elevado valor nutricional ao ser humano, especialmente flavonoides e antocianinas, pois possuem caráter antioxidante, os quais revelam grande capacidade de reagir com radicais livres (Rice-Evans et al., 1996), o que os torna extremamente benéficos ao 
organismo. Entre os compostos bioativos que podem ser encontrados nos alimentos, as antocianinas estão entre os mais comuns e importantes, sendo encontrados em uma ampla gama de frutas. As antocianinas, particularmente, apresentam sua importância nutricional relacionada com o combate aos processos oxidativos das células, amenizando assim os danos cumulativos que podem desencadear doenças como o câncer, cardiopatias e cataratas (Santos et al., 2008).

Um dos fatores que mais prejudicam a conservação dos alimentos é a água contida neles, pois sem ela é possível desacelerar o processo de degradação natural da matéria-prima, aumentando sua durabilidade (Torregianni et al., 2001). Devido a isso, faz-se uso do estudo sobre o comportamento da capacidade nutricional destes alimentos perante processos físicos que promovem a retirada parcial da umidade do alimento, como o processo de secagem (Krokida $e t$ al., 1998). Através da utilização do processo de secagem com ar quente podem ocorrer perdas de alguns componentes presentes, e devido a isso torna-se interessante o estudo de como estas substâncias (compostos bioativos) se comportam durante o processo de secagem.

Logo, o objetivo deste trabalho foi avaliar a cinética de degradação dos compostos bioativos (antocianinas) quando expostos ao processo de secagem convectiva em leito fixo na temperatura de $80{ }^{\circ} \mathrm{C}$ e velocidade do ar de $2 \mathrm{~m} / \mathrm{s}$.

\section{MATERIAIS E MÉTODOS}

\subsection{Matéria-prima}

Como matéria-prima do estudo foi utilizada a amora-preta cultivar Tupy, proveniente do município de Bagé/RS. A análise de umidade da amostra in natura foi feita através do método gravimétrico de secagem em estufa a $105^{\circ} \mathrm{C}$ durante $24 \mathrm{~h}$. A amostra foi mantida congelada a uma temperatura de $-5{ }^{\circ} \mathrm{C}$ até ser utilizada, sendo posteriormente descongelada sob refrigeração por $24 \mathrm{~h}$. Para preparar as amostras, as amoras descongeladas foram processadas em um moinho de hélice mantendo o tempo de processamento constante para todas as amostras, para então proceder a etapa de secagem. A Figura 1 apresenta os frutos utilizados neste trabalho.

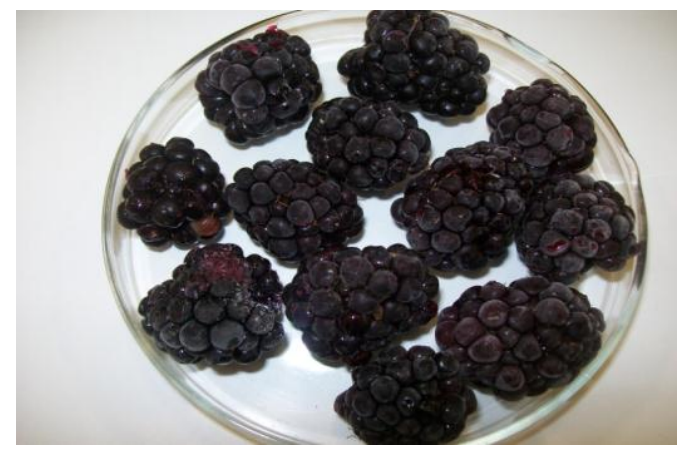

Figura 1 - Frutos de amora-preta. 


\subsection{Equipamento experimental}

Utilizou-se um secador de leito fixo com fluxo paralelo de ar, conforme mostrado na Figura 2 para realização da secagem da amora-preta.

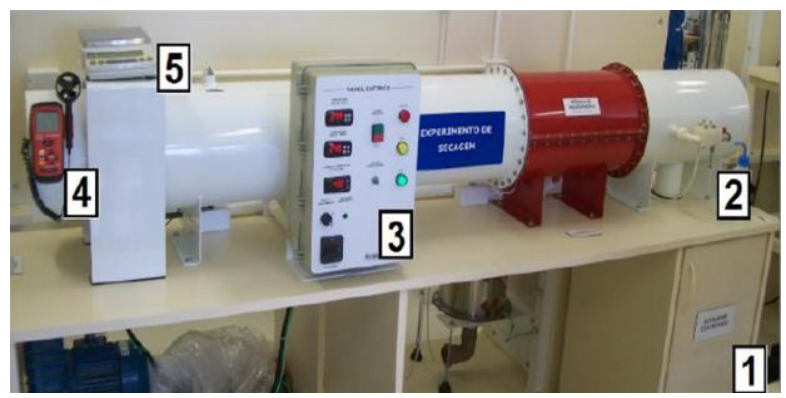

Figura 2 - Foto do secador utilizado.

Na Figura 2 observa-se o compartimento onde tem-se o soprador (1), um psicrômetro (2), o painel de controle (3), o anemômetro (4) e uma balança digital (5). A amostra ficou conectada a uma balança, no centro da tubulação, com escoamento paralelo de ar quente em velocidade de 2 $\mathrm{m} / \mathrm{s}$, tendo sua massa constantemente verificada. Este processo foi realizado na temperatura de 80 ${ }^{\circ} \mathrm{C}$.

Para o estudo da degradação das antocianinas durante a secagem foram feitos 4 experimentos com diferentes tempos de duração (35 min, 1h10, 1h45 e 2h20), sendo este número definido em testes preliminares.

\subsection{Quantificação de antocianinas totais}

Para a quantificação das antocianinas foi escolhido o método de FULEKI e FRANCIS (1968) (Teixeira et al., 2008), pois este foi testado em trabalhos anteriores e se mostrou mais satisfatório dentro das condições da pesquisa. O método de extração das antocianinas foi realizado utilizando como solução extratora etanol:água (70:30), seguido do ajuste do pH em 2, para melhor estabilização das antocianinas. Após realizar a etapa de filtração à vácuo as amostras foram analisadas em um espectrofotômetro em um comprimento de onda de $535 \mathrm{~nm}$.

Os valores de absorbâncias foram aplicados na Equação 1, que descreve a quantidade de antocianinas presentes na amostra, ajustada para o procedimento utilizado, e também para o tipo de antocianina predominante da amora-preta (cianidina-3-glicosídeo).

$$
A n t T=\frac{D O \times V_{1} \times V_{2} \times 1000}{V_{A i q} \times m \times 982}
$$

em que $D O$ que é a densidade ótica do extrato diluído, $V_{1}$, volume total do extrato concentrado em $\mathrm{mL}, V_{\text {alq }}$, volume da alíquota do extrato primário a ser diluída para fazer o extrato secundário, $V_{2}$, volume total do extrato diluído em $\mathrm{mL}, m$ é a massa da amostra em gramas, 1000 é o fator de correção para que resultado seja expresso em 100 gramas de amostra, $E_{1}^{19 \%}$ é o 
coeficiente de extinção (982).

\section{RESULTADOS E DISCUSSÃO}

A Tabela 1 apresenta os resultados para a umidade presente nas diferentes amostras (in natura e secas).

Tabela 1 - Valores de umidade para as diferentes amostras

\begin{tabular}{|c|c|c|c|}
\hline Amostra & Tempo de secagem (min) & Umidade $(\%$, b.u. $)$ & Umidade $\left(\mathrm{g}_{\text {água }} / \mathrm{g}_{\text {s.s. }}\right.$ b.s. $)$ \\
\hline in natura & 0 & $85,9 \pm 0,22$ & $6,08 \pm 0,11$ \\
\hline Amostra 1 & 35 & $72,9 \pm 0,48$ & $2,69 \pm 0,07$ \\
\hline Amostra 2 & 70 & $53,1 \pm 0,68$ & $1,13 \pm 0,03$ \\
\hline Amostra 3 & 105 & $30,7 \pm 2,96$ & $0,45 \pm 0,06$ \\
\hline Amostra 4 & 140 & $18,6 \pm 0,61$ & $0,23 \pm 0,01$ \\
\hline
\end{tabular}

Valor médio \pm desvio médio $(\mathrm{n}=3)$

Através da Tabela 1 pode-se observar que a secagem na temperatura de $80{ }^{\circ} \mathrm{C}$ possibilitou a remoção de grande parte da umidade presente na amostra in natura. A partir dos dados de cinética de secagem da amora-preta obteve-se o gráfico apresentado na Figura 3, em que relaciona-se a umidade da amostra (b.s.) com o tempo de secagem.

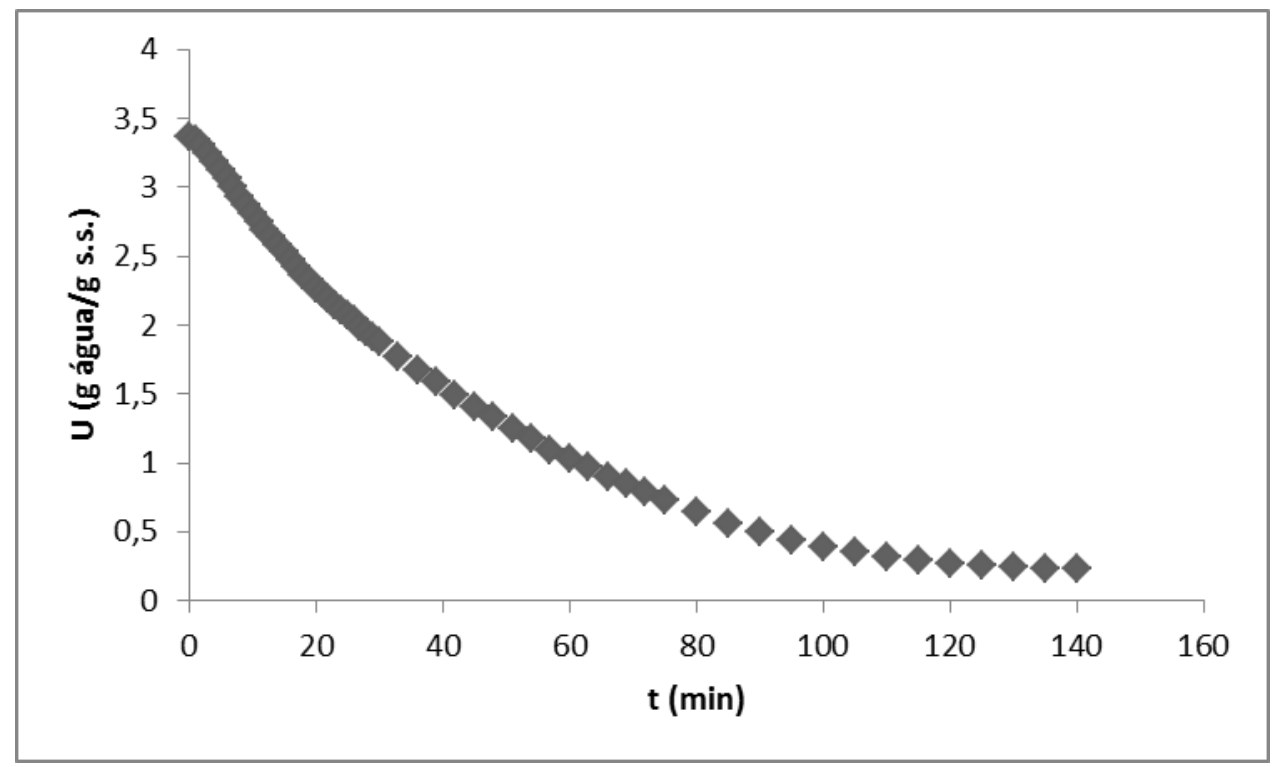

Figura 3 - Cinética da secagem realizada a $80{ }^{\circ} \mathrm{C}$.

Através da Figura 3 verifica-se que a curva apresentou formato típico obtido para secagem 


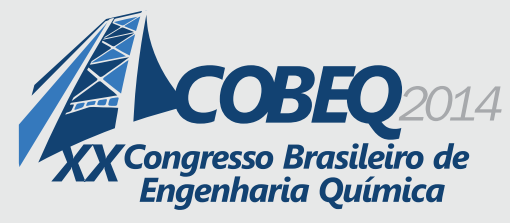

19 a 22 de outubro de 2014
Florianópolis/SC

de frutas com elevado conteúdo de umidade inicial, uma vez que os resultados indicam que a secagem ocorreu inicialmente em período de taxa constante seguido de um período de taxa decrescente. De acordo com a literatura, a presença da taxa constante esta relacionada à grande quantidade de água presente no material, sendo evaporada como água livre, enquanto que o período de taxa decrescente pode ser relacionado com a redução da taxa de secagem pela diminuição da superfície úmida, uma vez que no fim deste período o produto se encontra em equilíbrio com o ar de secagem (Lima, 1995). Durante o período em que a curva se comporta como uma reta tem-se a retirada constante da água, sendo esta a umidade se encontra nas camadas mais próximas da superfície e pode ser retirada mais facilmente da amostra. Após este período a perda de água da amostra para o meio começa a se tornar cada vez menor e menos significativa, estando esta relacionada com a presença de umidade no interior da estrutura do material. O estudo deste comportamento é de grande valia para se determinar até que ponto é desejado a perda de umidade, uma vez que a partir de certo valor esta se torna inviável devido ao elevado gasto energético.

Na Tabela 2 podem-se observar os conteúdos de antocianinas presentes nas amostras in natura e secas com diferentes tempos.

Tabela 2 - Quantificação das antocianinas presentes nas amostras (base seca)

\begin{tabular}{|c|c|c|}
\hline Amostra & Tempo de secagem (min) & $\mathrm{mg}$ de antocianinas/100 g s.s. \\
\hline in natura & 0 & $466,38 \pm 18,30$ \\
\hline Amostra 1 & 35 & $464,79 \pm 12,71$ \\
\hline Amostra 2 & 70 & $340,08 \pm 25,35$ \\
\hline Amostra 3 & 105 & $291,92 \pm 2,46$ \\
\hline Amostra 4 & 140 & $353,30 \pm 10,73$ \\
\hline
\end{tabular}

Valor médio \pm desvio médio $(\mathrm{n}=2)$

Com relação aos resultados obtidos para a cinética de degradação das antocianinas, pode-se ressaltar que estas diminuíram no decorrer dos experimentos. A amostra seca por 140 min teve redução de $24,25 \%$, se comparada à amostra in natura, sendo este resultado inferior ao reportado por Rocha (2013) para a secagem de amora-preta na temperatura de $40{ }^{\circ} \mathrm{C}$, em que foram relatadas perdas de $75 \%$ do conteúdo das antocianinas presentes.

O resultado obtido para a mostra seca em 105 min não encontra-se de acordo com o esperado, podendo este estar relacionado com a técnica de preparo das amostras para a realização da análise de antocianinas, pois as amostras apresentaram diferentes consistências devido aos diferentes níveis de umidade, e assim a amostra com menor umidade foi mais facilmente macerada, devido a sua natureza quebradiça. Durante a realização das análises observou-se que as amostras in natura e a amostra 4, com menor porcentagem de umidade, se solubilizaram mais facilmente na solução extratora do que a Amostra 3 e a Amostra 2, e isto pode influenciar o processo de extração, podendo ocasionar a diferença apresentada na tabela acima. Na Figura 4 pode-se verificar a aparência de algumas 
amostras, em que é possível perceber a consistência em que estas se encontram.

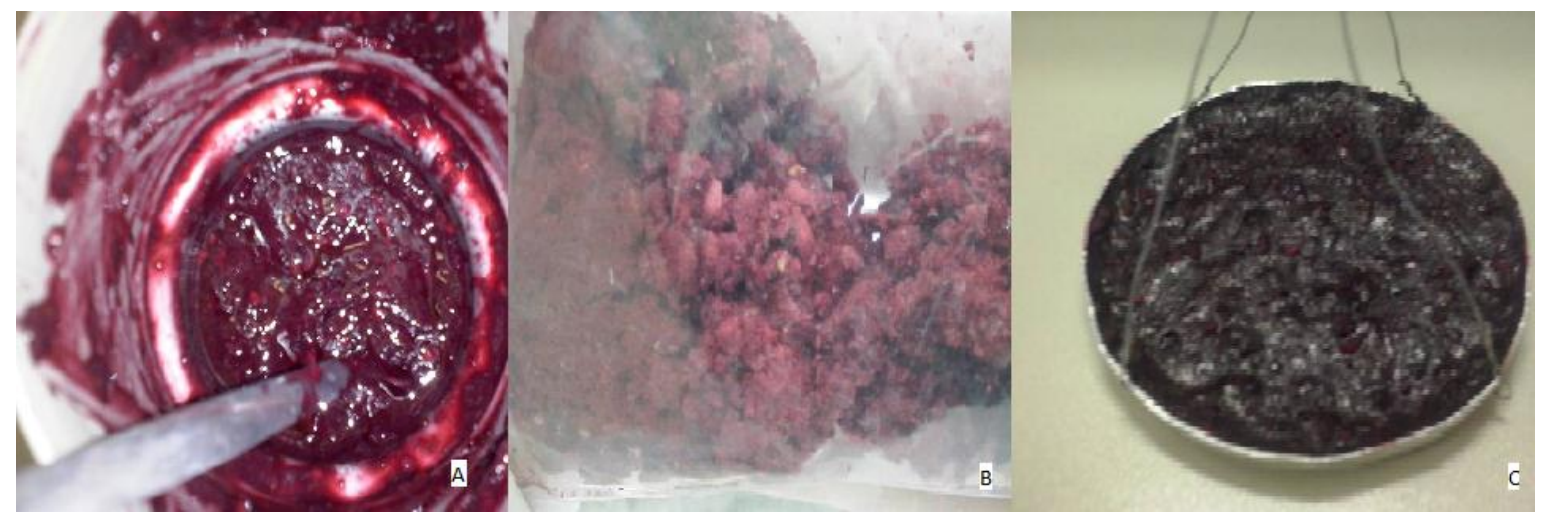

Figura 4 - Amostras utilizadas, em A a amostra in natura após o preparo, em B a amostra seca em 140 min e em C a amostra seca em 105 min.

\section{CONCLUSÃO}

Os resultados da cinética de secagem mostraram que o processo permitiu a diminuição do conteúdo de umidade, o que possibilita a estabilização do produto final por um maior período de tempo. Através das análises foi possível verificar que o conteúdo de antocianinas diminui no decorrer do experimento de secagem. Entretanto, foram observadas menores perdas para o conteúdo de antocianinas, se comparado com a literatura da área, sendo que para a secagem com duração de 140 min o conteúdo de antocianinas apresentou redução de $24,25 \%$.

\section{REFERÊNCIAS}

HARBORNE, J.B.; WILLIAMS, C.A. Advances in flavonoid research since 1992. Phytochemistry, v. 52, p. 481-504, 2000

KROKIDA, M. K.; TSAMI, E.; MAROULIS, Z. B. Kinetics on color changes drying of some fruits and vegetables. Drying Technology, v. 16, n. 3, p. 667-685, 1998.

KUSKOSKI, E. M.; ASUERO, A. G.; MORALES, M. T.; FETT, R. Frutos tropicais silvestres e polpas de frutas congeladas: atividade antioxidante, polifenóis e antocianinas. Cienc. Rural v. 36, n. 4, Santa Maria jul./ago., p. 1283-1287, 2006.

LIMA, A. C. C. de. Análise experimental da secagem de feijão em leito fixo, leito de jorro e leito de jorro fluidizado. Dissertação de mestrado EQ, Universidade Estadual de Campinas. Campinas - SP, 1995.

RICE-EVANS, C. A.; MILLER, N. J.; PAGANGA, G. Structure-antioxidant activity relationships of flavonoids and phenolic acids. Free Radical Biology Medicine, v.20, n. 7, p.933-956, 1996. 
MACHADO, F. R. Influência das condições de secagem sobre o conteúdo de antocianinas presente na amora-preta (Rubus spp.), Trabalho de Conclusão de Curso-EQ, Unipampa, 2013.

SANTOS, G. M.; MAIA, G. A.; SOUZA, P. H. M.; COSTA, J. M. C., FIGUEIREDO, R. W.; PRADO, G. M. Correlação entre atividade antioxidante e compostos bioativos de polpas comerciais de açaí (Euterpe oleracea Mart). Archivos Latinoamericanos de Nutricion, v. 58, n. 2, 2008.

TEIXEIRA, L. N.; STRINGHETA, P. C.; OLIVEIRA, F. A. Comparação de métodos para quantificação de antocianinas. Revista Ceres, v. 55, n. 4, julho-agosto, p. 297-304, 2008.

TORREGIANNI, D.; BERTOLO, G. High-quality fruit and vegetable products using combined processes. Osmotic dehydration \& Vacuum Impregnation - Aplication in Food Industries. p. 3-9, 2001. 